\title{
New Brunswick prescription drug plan hopes to avoid pitfalls of other provinces
}

$\mathrm{N}$ ew Brunswick waited a long time for a prescription drug plan but it may now have the best one in Canada, according to Steve Morgan, who studies pharmaceutical policy at the University of British Columbia in Vancouver.

"New Brunswick learned not to make the mistake of the western provinces, which only cover prescription drug costs once they exceed about 3\% of income," says Morgan. "It goes a lot further than the catastrophic drug plans in other provinces."

New Brunswick is the last province to enact a drug plan. Tabled in the provincial legislature on Dec. 10, the plan calls for a public insurance program to cover the costs of all drugs on the province's prescription drug formulary.

During the first phase, starting May 2014, people can choose to enrol in the plan. Premiums will range from $\$ 800$ to $\$ 2000$ per year, depending on income. There is no deductible or cap on coverage, although there will be a $30 \%$ copay at pharmacies, up to a maximum of $\$ 30$.

The second phase begins April 2015, when all citizens will be required to have prescription drug insurance, either through private plans or the provincial plan. Private plans will be required to at least match the coverage offered by the provincial plan. Premiums are expected to drop during this phase as more people sign up.

Employers who don't provide drug coverage will not be required to contribute to the public program or set up their own private plans, though they can voluntarily pay premiums for their employees. But these businesses will eventually have to help pay for the cost of the provincial plan, according to Health Minister Ted Flemming.

The New Brunswick plan differs markedly from some other pharmacare systems across Canada. British Colum-

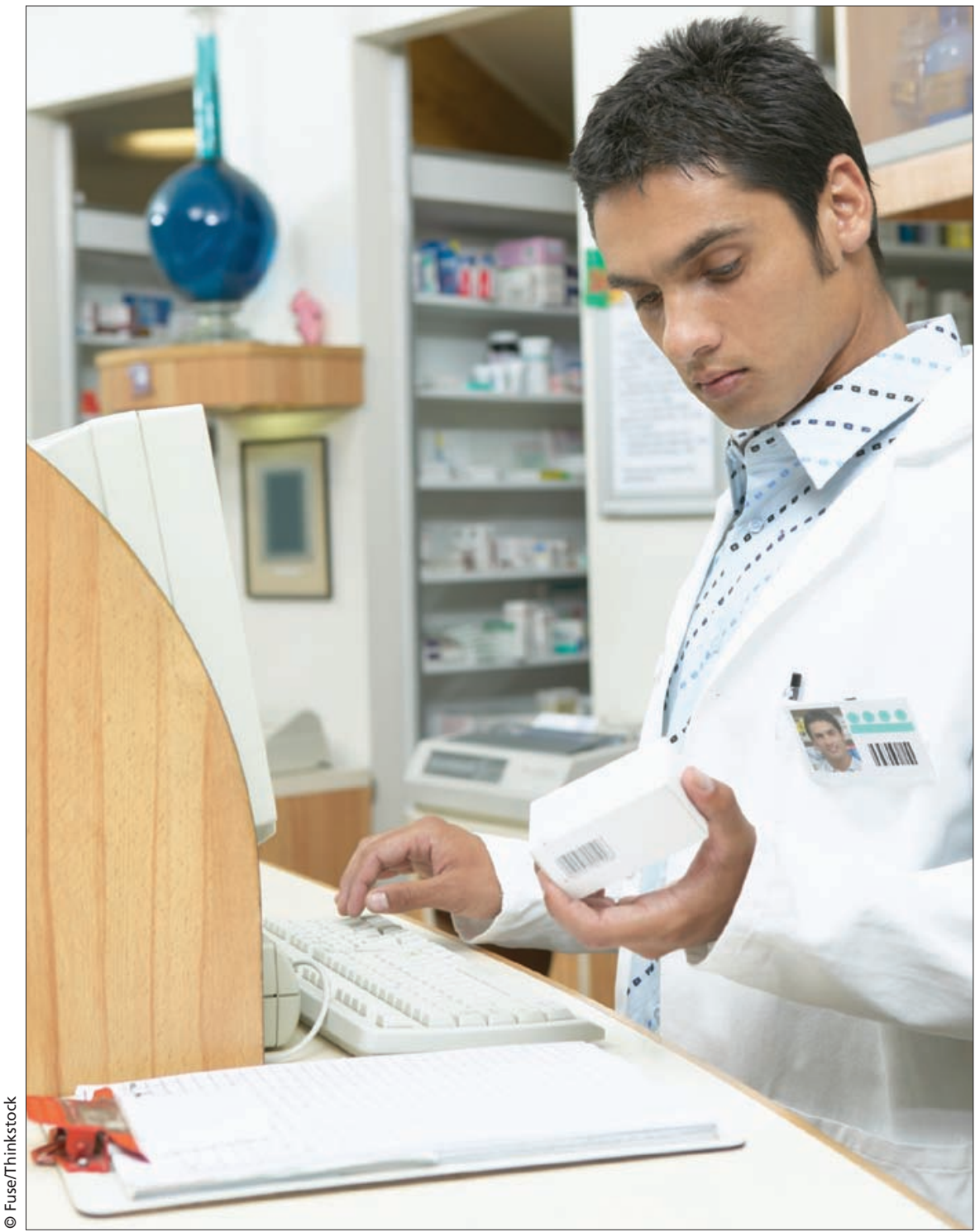

The New Brunswick drug plan has no deductible or cap on coverage, although there will be a $30 \%$ copay at pharmacies, up to a maximum of $\$ 30$.

bia's Fair PharmaCare Plan, for example, subsidizes drug costs only after they exceed $2 \%-4 \%$ of net family income. Ontario's plan combines neartotal coverage for seniors, with a catastrophic plan for younger people that kicks in at around $4 \%$ of net household income.

The problem with these models, says Morgan, is that $3 \%-4 \%$ of income is quite a high deductible, and people still face substantial out-of-pocket expenses for drugs. They also leave the government with little bargaining power to control prices. "I'm glad New Brunswick's advisory committee recommended that a catastrophic plan was not a good option, and went for something more comprehensive," he says.

Although Premier David Alward 
had promised a catastrophic drug plan in the 2010 election, the advisory committee tasked with reviewing and recommending options approached it from a poverty-reduction standpoint, according to Heidi Liston, director of drug utilization and pharmaceutical services at the New Brunswick Department of Health and Wellness.

"We didn't want to look at plans with high deductibles, which can create a barrier at the pharmacy," says Liston.

The plan that most closely resembles New Brunswick's version is the one in Quebec, which requires those without drug insurance through employers to buy it from the government. But these types of plans also have their pitfalls, warns Morgan.
Quebec's public drug insurance is considered by some to be the plan of last resort. It isn't self-financing and must be topped up out of general government revenues. "The private plans skimmed off all the best clients, leaving the public one with just high-cost, highrisk populations who don't have much money," says Morgan.

The best way for New Brunswick to avoid that fate, he says, would be for the public plan to become universal "by stealth," essentially outcompeting and replacing private insurance. That would give the government enormous purchasing power in negotiations with suppliers, he says.

But that is unlikely to happen, says Liston, because the government is keen to maintain a mix of public and private insurance options. Besides, the public plan, when it becomes mandatory, will have a broad base of members, she adds. Around 20\% of New Brunswickers lack drug coverage, and the demographics of that group differ little from that of the general population.

Morgan expects that few people will enrol in the public plan during the voluntary phase because of high premiums. When it becomes mandatory, however, the plan has the potential to drive real improvement in health care in the province, he says. "The test will be over the next two years." - Brian Owens, St. Stephen, NB

CMAJ 2014. DOI:10.1503/cmaj.109-4688 